\title{
Mechanism on Redistribution Synthesis of Dichlorodimethylsilane by AlCl3/ZSM-5(3T)@ -Al2O3 Core-shell Catalyst
}

\author{
wenyuan $\mathrm{xu}^{1}$, Yongbing Cheng ${ }^{1}$, Yan Wang ${ }^{1}$, Suying $\mathrm{Li}^{1}$, Mengsha Shen ${ }^{1}$, Hongkun \\ Huang ${ }^{1}$, Mengyin Liao ${ }^{1}$, Jiaxi Peng ${ }^{1}$, Shunmin Ding $^{2}$, Xi Chen ${ }^{1}$, and Shaoming Yang ${ }^{1}$ \\ ${ }^{1}$ East China Jiao Tong University \\ ${ }^{2}$ Nanchang University
}

April 22, 2021

\begin{abstract}
The redistribution method plays an important role in addressing the issue of organosilicon by-product in the direct synthesis of dichlorodimethylsilane, and the redistribution mechanism is still a topic of debate. The redistribution by ZSM-5(3T)@ $\gamma-$ $\mathrm{Al} 2 \mathrm{O} 3$ core-shell catalyst and post-modified AlCl3/ZSM-5(3T)@ $\gamma-\mathrm{Al} 2 \mathrm{O} 3$ catalyst was technically performed using the Density Functional Theory (DFT) at the level of B3LYP/6-311++G(3df,2pd). The result shows that No.1 active site of ZSM-5(3T)@ $\gamma-$ $\mathrm{Al} 2 \mathrm{O} 3$ core-shell structure has a significant effect on the activity of the catalyst. Indicating that the active center involved in the reaction is $\mathrm{H}$ provided by Al-O-H bond, which is an obvious catalytic active center of Bronsted acid. Furthermore, postmodified AlCl3/ZSM-5(3T)@ $\gamma-\mathrm{Al} 2 \mathrm{O} 3$ catalyst is in more favor of redistribution reaction comparing with ZSM-5(3T)@ $\gamma-\mathrm{Al} 2 \mathrm{O} 3$ core-shell catalyst. It ascribes to the robust Lewis site of aluminum chloride favorable modification.
\end{abstract}

\section{Hosted file}

paper.pdf available at https://authorea.com/users/409361/articles/519083-mechanism-onredistribution-synthesis-of-dichlorodimethylsilane-by-alcl3-zsm-5-3t-\%CE\%B3-al2o3-core-

shell-catalyst 